\title{
Mathematical Modeling in Connecting Concepts to Real World Application
}

\author{
Zhonghe Wu and Lijun Ye
}

\section{Aim and Rationale}

In recent years, achieving mathematics proficiency has received notable attention [RAND 2003; National Research Council (NRC) 2001] What useful, appropriate, practical, and effective strategies can be developed and used to enhance student proficiency in mathematics is still a puzzle to mathematics educators. This urgent need becomes a challenging task for mathematics educators seeking research-based strategies to support classroom teachers to enhance their teaching leading to student proficiency.

The Mathematical Modeling is a research-based teaching model (Lesh and Zawojewski 2007; Niss et al. 1991) that builds conceptual understanding and problem solving skills. The mathematical modeling also reflects the core components of proficiency defined by research studies (Hill and Ball 2004; NRC 2001; RAND 2003) — conceptual understanding, computational skills, problem solving, mathematical reasoning, and mathematical disposition.

Organizers Co-chairs: Zhonghe Wu (USA), Lijun Ye (China); Team Members: Shuhua An (USA), Zhongxiong Fan (China), Ling Wang (China); Liaison IPC Member: Morten Blomhoej (Denmark).

\footnotetext{
Z. Wu ( $₫)$

National University, California, USA

e-mail: zwu@nu.edu

L. Ye

Hangzhou Normal University, Hangzhou, China

e-mail: yeatsylj@126.com

(C) The Author(s) 2015

S.J. Cho (ed.), The Proceedings of the 12th International Congress on Mathematical Education, DOI 10.1007/978-3-319-12688-3_76
} 


\section{Key Questions}

The following five broad areas frame the territory of the discussion.

- What is Mathematics Modeling? Why Mathematics Medeling?

- What is the relationship between mathematical modeling and mathematical proficiency? What does role of Mathematics Modeling play in teaching and learning mathematics for K-12 students?

- How is mathematical modeling used in primary school?

- How is mathematical modeling used in secondary school?

- What are the challenges and issues of mathematical modeling in teacher professional development?

Open Access This chapter is distributed under the terms of the Creative Commons Attribution Noncommercial License, which permits any noncommercial use, distribution, and reproduction in any medium, provided the original author(s) and source are credited. 